
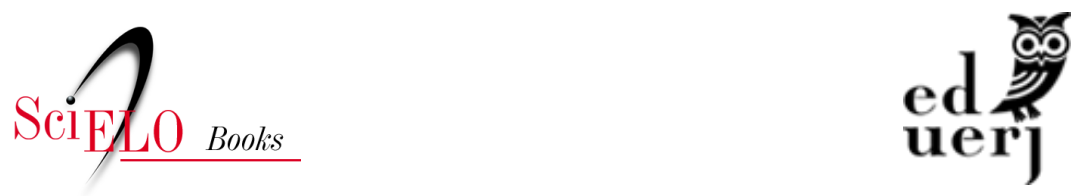

\title{
7. Entrevista com Estela dos Santos Abreu
}

\author{
Vanessa Massoni da Rocha
}

\section{SciELO Books / SciELO Livros / SciELO Libros}

ROCHA, V. M. Entrevista com Estela dos Santos Abreu. In: Tradução em (ent)revista: Simone Schwarz-Bart e as tradutoras brasileiras [online]. Rio de Janeiro: EDUERJ, 2021, pp. 53-71. Letras UERJ collection. ISBN: 978-65-9911115-0. https://doi.org/10.7476/9786599111150.0007.

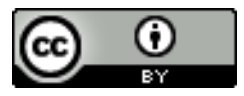

All the contents of this work, except where otherwise noted, is licensed under a Creative Commons Attribution 4.0 International license.

Todo o conteúdo deste trabalho, exceto quando houver ressalva, é publicado sob a licença Creative Commons Atribição 4.0.

Todo el contenido de esta obra, excepto donde se indique lo contrario, está bajo licencia de la licencia Creative Commons Reconocimento 4.0. 


\section{Entrevista com Estela dos Santos Abreu}

1. Como você se apresentaria? Como nasce sua verve de tradutora e por que decidiu dedicar-se por tantos anos a esse ofício?

Nasci em Santos em 1932, vivi muitos anos na cidade de São Paulo e, ao concluir o Curso de Direito (profissão não exercida), fui estudar Ciências Sociais em Paris, onde morei de 1965 a 1975. Com a sorte de lá estar em 1968, ano que muito me ensinou!, defendi, em 1974, tese de doutorado na Sorbonne sobre o advento dos meios de comunicação de massa. Nessa época, traduzi muito, do português para o francês: teses, relatórios e trabalhos de colegas, mas nunca profissionalmente. Como bolsista, não se podia aceitar trabalho remunerado.

De retorno ao Brasil, lecionei Sociologia e Metodologia da Pesquisa no Mestrado em Educação da UFF, de 1980 a 1997. Só depois de aposentada dediquei-me de fato à tradução. Até agora, foram oitenta e cinco livros, na maioria ensaios. Gosto muito de literatura, mas minha sina parece ser o texto teórico. 
O começo como profissional nasceu do pedido de um amigo economista, professor em Paris: ele "devia" uma tradução à editora carioca Rose Marie Muraro e não achava tempo para iniciar o trabalho. Como eu acabava de defender a tese e regressava ao Brasil, pediu-me que o fizesse por ele.

Nunca havia traduzido profissionalmente e nem me via como tradutora.

Não me lembro bem como foi o processo dessa primeira tradução. Devo ter procurado muito, consultado amigos. Sei que entreguei o texto, publicado pela Vozes, em 1976. A partir daí, não parei mais.

Nunca fiz curso nem recebi educação formal para traduzir. Foi pela dura experiência e muita consulta aos amigos (incansáveis) que fui aprendendo. Até hoje conto com eles!

Para mim, a tradução é uma cachaça. Umberto Eco diz que traduzir é dizer quase a mesma coisa. E dizer quase a mesma coisa em outra língua é tarefa muito difícil. Não fico satisfeita. Sofro, resmungo, porque acho que não disse bem, que não escolhi a melhor palavra. Pode parecer exagero, mas é assim. Não costumo reler as traduções publicadas. Releio várias vezes antes de entregar o original à editora. Mas, depois, não. Chega de sofrer!

Não há truques. Não conheço nenhum. Só conheço um procedimento: ler muito bem o texto, tentar vertê-lo o mais fielmente possível, sempre com a maior correção, com a maior leveza; tentar não desmerecer o original. Não existe isso de trair. Só não estragar o original já ajuda muito(risos). É um prazer traduzir. Às vezes, me acabo, porque há textos dificílimos.

Um dos livros que traduzi e mais aprecio é $A$ sociedade do espetáculo, do Guy Debord, não só pela importância do conteúdo quanto pela capacidade do autor de ver o homem e o mundo de maneira ampla. Debord é um absoluto profeta da inteligência. Não falou de temáticas incertas, conhecia realmente os rumos que a sociedade tomaria e 
tomou, para tornar-se o lamentável espetáculo que temos hoje. Entre outros muito queridos, menciono os autores Gaston Bachelard e Jean-Paul Sartre.

Recentemente, traduzi a Sociologia do Trabalho na França, publicada pela EdUSP, de autoria de Lucie Tanguy, amiga de muitos anos. Num primeiro momento, o livro parecia simples, o texto era bastante palatável. Tinha, contudo, um vocabulário de novas técnicas e umas 200 siglas que tive de desvendar. Exaustivo, porque havia até incongruências. Traduzir é sempre um desafio. Com ciladas.

\section{Você recebeu em 1994 o Prêmio Biblioteca Nacional na categoria} tradução pelo conjunto da obra. Qual a importância desse prêmio? É possível para o tradutor ter reconhecimento acadêmico? Quais os maiores desafios para o trabalho de tradução no Brasil?

Sinceramente, eu não me lembrava desse prêmio. Além das traduções, iniciei com Hervé Renard, do Ministério da Cultura francês, um mapeamento dos autores brasileiros traduzidos na França. Desenvolvi essa atividade por mais de vinte anos numa parceria com o Consulado da França, a Biblioteca Nacional e a Academia Brasileira de Letras. O prêmio não foi por uma determinada tradução. Deve ter sido pelo conjunto desse trabalho, mas realmente não tenho certeza.

Em 2008, a ABL me concedeu a medalha Machado de Assis. Disso eu me lembro. Do prêmio de 1994, realmente não sei.

(Estela pega sua agenda para anotar o nome do prêmio do qual não se lembra. Diz que precisa pesquisar para se lembrar do que se trata) Ah! já sei que prêmio é esse. Recebi sim. Foi pelo conjunto da obra. Quem me entregou foi o Affonso Romano de Sant'Anna, presidente da Biblioteca Nacional. Tenho foto da cerimônia. Eu fizera também uma tradução para a Biblioteca no lugar de alguém que desistiu do trabalho, atrasando muito o programa de publicação. 
3. As obras por você traduzidas foram selecionadas por escolhas afetivas, acasos, sugestões editoriais? Em outras palavras, qual o caminho percorrido entre você e as obras que traduz?

Tudo começa pelo editor. Alguns livros não aceitei, mas foram poucos, nestes mais de quarenta anos de tradução. Acabei de recusar um, no início de 2016, "por causa da minha idade”, afirmei cinicamente. Eram vinte e três páginas só de Sumário! E o autor fazia referência a um "plano" que não consegui captar...

Durante todos esses anos, sugeri poucos livros aos editores. A iniciativa é quase sempre deles: oferecem o texto e, se me agrada, aceito. Trabalhei com várias editoras. No Rio de Janeiro: Marco Zero, José Olympio, Casa de Rui Barbosa, Vozes, Fundação Getúlio Vargas, Jorge Zahar, Nova Fronteira, Casa da Palavra, Rio Book's, Contraponto; em São Paulo: Moderna, Martins, Unesp, Edusp, Nobel, Globo, Scipione, Martins Fontes, Barcarolla; em Campinas: Papírus. E algumas outras.

4. Você traduz predominantemente romances? Por quê? É nesse gênero que você transita com maior desenvoltura?

A maior produção é de ensaios, os romances são menos numerosos, embora eu goste muito deles.

Traduzi em 2011 um livro de poemas: Fragmentos de um crepúsculo ferido, vigorosa denúncia sociopolítica de Célestin Monga (natural da República dos Camarões), de quem eu já traduzira dois ensaios.

Aos dezoito anos, ele foi à África do Sul e deparou com o horror do apartheid, experiência que muito o marcou. $\mathrm{O}$ original, de estrofes livres, sem rimas, foi publicado em francês por uma pequena editora no Canadá; aqui no Rio, a edição é bilíngue. Meu único percurso pela poesia. 
5. Você já participou de traduções em colaboração, trabalhando, por exemplo, com a tradutora Waleska Moysés. Quais os critérios que definem se uma obra será traduzida coletivamente?

Algumas traduções exigem especialistas, mas costumo trabalhar sozinha. No caso da Waleska, que, por sinal, foi minha aluna no Mestrado em Educação da UFF, ocorreu o seguinte: uma professora da Universidade Federal do Rio de Janeiro precisava com urgência da tradução de um livro de arquitetura porque o autor chegaria ao Rio para dar um curso.

Não havia tempo para um único tradutor fazer todo o trabalho. Como o livro era composto de um longo capítulo introdutório do autor e de textos de diversos colaboradores, dividi o trabalho com a Waleska. Foi possível porque eram textos autônomos, bastante diversificados. O trabalho de tradução coletiva supõe a autonomia de cada tradutor, contanto que se mantenham a harmonia e a consistência geral do texto.

6. O escritor quebequense Jacques Poulin publicou o romance $L a$ traduction est une histoire d'amour em 2006. Nesse romance, ele revela curiosidades do processo de tradução da tradutora Marine e do escritor Waterman, dentre as quais se destaca o fato de a tradutora usar as roupas do autor, visitar sua casa e andar por caminhos por ele percorridos. Nesse sentido, eu pergunto: a tradução é uma história de amor?

Acho que tem de ser uma história, em todo caso, de muito interesse por aquilo que ali está. Nem todos os livros traduzi por amor. Mas, uma vez começada a tarefa, vou até o fim. Não dá para abandonar. Houve textos que me custaram muito esforço, mas, depois que o processo acaba, fica tudo bem. Quando lembro das oitenta e cinco traduções, acho que teria deixado algumas pelo caminho. Umas trinta, caso me propusessem hoje, não teria aceitado. Na época, não tinha toda a clareza de opção. Mas alguns livros não foram para mim apenas 
matéria de trabalho, foram programas de vida, como $A$ sociedade do espetáculo. Foi fundamental o que esse livro me ensinou.

Há os que acho lindos, poderosos, como o da Simone Schwarz-Bart. Foi um enorme prazer - ainda agora renovado - ter feito essa tradução. Outros, contudo, foram dureza: deram muito trabalho e não me pareceram tão relevantes. Em todo caso, procuro fazer da melhor forma até o final. Minha costela portuguesa é telhuda, difícil de mudar.

\section{Como você definiria a arte da tradução? Reescrita?}

Parece-me que traduzir é um desafio no sentido de lidar com algo não evidente, incerto. É um contínuo buscar e escolher. Hoje, é claro, traduzo com mais facilidade do que há vinte anos.

Mas ainda há vezes em que a tradução está fluindo bem, quando, de repente, aparece um paredão. Procuro vencer a dificuldade sem tapear o leitor. Acho injusto que se diga algo errado ou menos próximo do que consta no original. A busca é pelo mais exato, mais similar. Persiste sempre para mim uma interrogação: de fato consegui fazer isso? Só li livros sobre tradução há poucos anos. Meus conhecimentos vêm da prática e quase nada da teoria. Tive uma grande sorte: o contato com Paulo Rónai. Trabalhamos juntos, frequentei a casa dele, pessoa extraordinária pela simplicidade, inteligência e generosidade. Conheci as traduções do Paulo, que são preciosas.

Recentemente, li Dire presque la même chose, de Umberto Eco. Traduzir textos de economia, por exemplo, talvez possa ser uma atividade de dizer a mesma coisa. No âmbito da literatura e de textos mais imaginativos, traduzir é dizer quase a mesma coisa. É sempre a tentativa de não deixar escapar a melhor palavra, a melhor expressão. Tenho convicção de que alguém pode traduzir muito melhor do que eu, com mais precisão do que eu. Sinto que faço o que me pedem da melhor forma possível, mas, ai de mim, pensar que está bom! 
8. Carlos Heitor Cony, no romance Quase memória, desenvolveu a teoria geral do quase ${ }^{1}$, ressaltando as limitações dos atos de lembrar e escrever. Podemos aludir também à incompletude do traduzir?

Eu li. Gosto muito desse romance. O "quase” nos acompanha. E não nos dá sossego...

\section{Você poderia revelar algumas curiosidades do seu processo de tradução?}

Antes eu começava a frase e, diante de uma dificuldade, parava, procurava resolver. Agora, se me vêm à mente quatro traduções para um mesmo adjetivo, escrevo as quatro, separando com traços vermelhos, e sigo em frente. Às vezes estará na página 180 a resposta sobre a melhor opção. A certeza é que, na página 10, ainda não dá para saber. Consulto também vários dicionários, e sobretudo pessoas, para buscar a tradução mais conveniente. Amigo é pra essas coisas...

Com relação ao ritmo de trabalho, costumo andar dois ou três quilômetros pelo Aterro do Flamengo todo dia bem cedo, tomar café e trabalhar sem interrupção até a hora do almoço. Ando por recomendação médica, ou seja, para ativar a circulação das artérias! Acorde cansada ou não, vou andar do mesmo jeito. Trabalho até meio-dia. Às vezes, preciso me lembrar de parar para almoçar. Há um vício na tradução,

Transcrevo, na íntegra, a teoria geral do quase de Cony (2003, p. 7):

Ao terminar meu nono romance (Pilatos), há mais de vinte anos, prometi a mim mesmo que, acontecesse o que acontecesse, aquele seria o último. Nada mais teria a dizer - se é que cheguei a dizer alguma coisa.

Daí a repugnância em considerar este Quase memória como romance. Falta-lhe, entre outras coisas, a linguagem. Ela oscila, desgovernada, entre a crônica, a reportagem e, até mesmo, a ficção.

Prefiro classificá-lo como "quase romance" - que de fato o é. Além da linguagem, os personagens reais e irreais se misturam, improvavelmente, e, para piorar, alguns deles com os próprios nomes do registro civil. Uns e outros são fictícios. Repetindo o anti-herói da história, não existem coincidências, logo, as semelhanças, por serem coincidências, também não existem.

No quase-quase de um quase-romance de uma quase-memória, adoro um dos lemas do personagem central deste livro, embora às avessas: amanhã não farei mais essas coisas. 
é um processo muito absorvente. Quando gosto do livro, retomo a tradução logo depois do almoço e posso traduzir até às 16 ou $17 \mathrm{~h}$.

Aí, já não encontro a palavra, empaco por nada, é hora de dar uma de inglês: faço um chá e, só depois, volto ao texto. Houve tempo em que cheguei a ficar trabalhando até meia-noite. Isso acabou. Trabalho no máximo sete ou oito horas por dia, o que não me custa, não é sacrifício. Atualmente, tento diminuir o ritmo, procuro ir ao cinema à tarde ou ver alguém. Quando a tradução é pesada, eu emendo, não tem sábado nem domingo. Não existe nada de inspiração: é dureza diante do teclado.

10. Nesse mesmo romance de Poulin, La traduction est une histoire d'amour, há a definição de tradução como transporte, transporte de língua ou transporte amoroso através da citação de Albert Bensoussan presente na epígrafe. Então eu pergunto: para você a tradução é um transporte? Que tipo de transporte?

Bensoussan encontrou uma boa definição, uma maneira diferente de falar. Traduzir é levar de um lugar para outro. Trata-se de um transporte de palavra, e amoroso. Por que precisa ser um ou outro? Para mim é fundamental gostar do que se está fazendo, não necessariamente dominar o assunto ou gostar dele, mas dedicar-se ao trabalho. Não traduzo de jeito nenhum autor de quem eu não goste. Tive sorte com os livros que traduzi. Não gostei imenso de todos, mas o sentimento passou longe do repúdio. Se for para traduzir textos que ferem convicções, eu os devolvo sem pestanejar ao interessado; na minha idade, não dá mais para aturar desaforo.

11. Você traduziu muitos escritores de expressão francesa originários de outros países ou departamentos. Refiro-me à guadalupense Simone Schwarz-Bart, ao haitiano René Depestre, ao belga Pierre Louys, ao austríaco André Gorz, só para citar alguns exemplos. Quais os caminhos que a levam a esses autores francófonos? Você 
reconhece desafios específicos nessas traduções com relação a textos em francês desenvolvidos na França?

Nunca foi escolha deliberada e mal tinha percebido isso. No fundo, como já disse, é a editora que oferece determinado livro. Estou tão acostumada com textos de natureza diversa que minha preocupação maior é não falsear, não errar. Para mim, Gorz escreve como qualquer francês. Pierre Louys é um francesão. São textos primorosos de grande qualidade literária. Pode ser falha da minha parte, mas não percebo grandes diferenças, do ponto de vista do trabalho de tradução, entre esses autores e os demais, a não ser quando é usado vocabulário específico, como no caso das Antilhas.

12. Antoine Berman, na obra Leépreuve de l'étranger, afirma que "a essência da tradução é ser uma abertura, diálogo, mestiçagem, descentramento" (2011, p. 16). Qual a sua opinião sobre essa afirmação? A tradução encarna o que o autor considera ser "a violência da mestiçagem" (2011, p. 16)? Você reconhece nos seus trabalhos alguma predileção pela francofonia?

Quem traduz deve estar muito atento à língua original e, ao mesmo tempo, fazer o texto tomar corpo e ser o mais fiel possível ao texto de origem. Procuro não desvirtuar essa tentativa.

\section{Como se iniciou o processo de tradução da obra Pluie et vent sur} Télumée Miracle? Como você descobriu essa obra?

Em 1984, fui chamada por Márcio Sousa, da editora Marco Zero, para traduzir o livro. Assim conheci a escritora e o romance. Foi meu segundo contato, como leitora e tradutora, com a literatura antilhana. No ano anterior, em 1983, tinha traduzido Pau de Sebo, do haitiano René Depestre, conjuntamente com Maria Wanda Maul de Andrade. 
14. O livro Pluie et vent sur Télumée Miracle foi traduzido em doze línguas. Trata-se da obra de Simone Schwarz-Bart com maior número de traduções. Ao que você atribui tal interesse?

É livro de evidente qualidade literária, que dá gosto ler, escrito de maneira inteligente, sempre surpreendente. Uma história muito possível, bonita e, ao mesmo tempo, reveladora do complexo e pouco conhecido universo antilhano, sua cultura, seu relacionamento humano. Sem dúvida, uma grande obra. Simone consegue prender o leitor e levá-lo à emoção. Acho que é um dos livros mais bonitos que já li. E, além da tradução, foi enorme o prazer de conhecer Simone na sua terra.

15. Durante o processo de tradução, você tem a curiosidade ou o método de trabalho de consultar uma tradução anterior em outro idioma? Em 1979 foi publicada Lluvia y viento sobre Telumea Milagro. Você conhece essa tradução?

Não conheço essa tradução nem nunca me passou pela cabeça descobrir traduções em outras línguas antes de fazer a minha - o que talvez fosse uma ajuda. O meu esforço é descobrir como dizer da melhor forma o que está escrito no original. Outras pesquisas, eu não faço. Sou mais preguiçosa do que você imagina.

16. Em entrevista, você já afirmou "não gosto de traduzir autor morto. Com o vivo, eu pergunto, troco ideias. Com morto não dá jeito..." (apud Melo, 2009, s/p). O trabalho a quatro mãos entre autor e tradutor é essencial para a tradução? Quais os problemas do autor morto e as benesses do autor vivo?

É uma sorte poder comunicar com o autor do texto original. Conversei muito com René Depestre ${ }^{2}$, por exemplo. Outros, como Simon Leys e

2 Estela dos Santos Abreu traduziu três obras de René Depestre: os romances Le mât de cocagne (1979), como $O$ pau-de-sebo (1983), tradução a quatro mãos com Maria Wanda Maul de Andrade; Hadriana dans tous mes rêves (1988), como Adriana em todos os meus sonhos (1996); e o livro de contos Alléluia pour une femme-jardin (I98I), como Aleluia para uma mulher-jardim (1988). Tal número de traduções (três romances de 
Guy Debord, que tanto aprecio, nunca encontrei. Na realidade, o livro devia bastar, mas gosto muito quando consigo consultar os autores. Com Thérèse Bertherat, fisioterapeuta francesa, foi uma longa convivência, desde 1977, ao traduzir seus cinco livros ${ }^{3}$ para o português. Nossa amizade foi repleta de alegrias, encontros e viagens. Célestin Monga $^{4}$ é um amigo que costuma vir ao Brasil. Simone Schwarz-Bart é uma mulher maravilhosa. Gosto muito de criar esses laços que também ajudam a sanar dúvidas sobre as traduções.

\section{Você esteve na Guadalupe e encontrou a escritora Simone Schwarz-Bart. Como foi esse encontro?}

Foi em novembro de 1985. Eu tinha estado em Paris para uma reunião com editores e, de lá, peguei um voo para Pointe-à-Pitre. Havíamos combinado por telefone, e Simone me esperava. Eu acabara de traduzir o livro dela e tinha muitas dúvidas. Lá passei duas semanas. (Fui por iniciativa própria, arquei com todos os custos da viagem e da estada, é claro).

Depestre e um de Schwarz-Bart) confere à Estela um título importante: a tradutora que mais traduziu literatura antilhana para o português no Brasil, até o presente momento. Seu trabalho, a ser celebrado sem moderação, contribui sobremaneira para a divulgação da literatura antilhana no Brasil tanto junto aos leitores não francófonos quanto àqueles que têm interesse em ler a obra em português. Em tempos de preços proibitivos do valor do euro e das taxas de entrega para o Brasil em sites internacionais, a leitura do livro em português se torna uma relevante porta de acesso para leitores francófonos, inclusive. Cabe salientar ainda aqueles que, por apreço à tradução, propõem-se a realizar uma leitura comparativa da obra nas duas línguas, o que foi meu caso.

3 Trata-se dos livros $O$ corpo tem suas razões: antiginástica e consciência de si (200I), As estações do corpo (200I), O correio do corpo: novas vias da antiginástica (200I), A toca do tigre (2002) e Quando o corpo consente (20I3). Todos publicados pela Martins Fontes. As datas referem-se às edições mais recentes.

4 Dele, Estela traduziu o ensaio Niilismo e negritude: as artes de viver na África, e o ensaio Um banto em Washington, seguido de Um banto em Djibuti, publicados em 2010 pela Martins, além do livro de poemas Fragmentos de um crepúsculo ferido (publicado em $201 \mathrm{I}$ pela Contraponto). 
Ela possuía um brechó "inteligente” no centro da cidade com produtos maravilhosos, como móveis antigos que ela mandava restaurar, objetos variados e até vestidos à la Joséphine, da época de Napoleão. Ela me presenteou com alguns, uma beleza. Entendia de tudo, com muito gosto, e sabia dirigir os operários.

Sentada numa poltrona, recebia constantes visitas de moças que passavam para lhe pedir conselhos. Escutava-as com atenção, dava sugestões, creio eu. Tudo com alegria e serenidade.

Recebeu-me muito bem, respondeu a todas as perguntas, que não foram poucas. Realmente tive muitas dúvidas ao longo da tradução. Expliquei a dificuldade em encontrar o vocabulário para coisas inexistentes no Brasil, como certos frutos, árvores, animais.

Há, por exemplo, diferentes nomenclaturas no romance para bichos que rastejam pelas paredes como se fossem lagartixas. Não são lagartixas, são espécies similares, cada uma com um nome diferente. Importantes também eram as vendedoras na rua com tabuleiros de frutas, quase todas começando pela palavra "pomme" - nada a ver com maçã, é claro. Foi um grande aprendizado.

Depois de duas ou três visitas ao brechó, ela me convidou para ir à sua casa. Na época, há mais de 35 anos, a cidade tinha um centro variado, um bairro residencial não muito longe do centro, ao qual se seguia uma área mais afastada que parecia uma floresta. Com poucas casas. Era lá que ela morava, em Goyave, perto dos pais. Casa muito bonita, bem planejada, toda branca, no meio daquele verde exuberante.

Era de um bom gosto extraordinário. Ela estava sozinha. O marido e os dois filhos adolescentes estavam em Paris. André Schwarz-Bart ${ }^{5}$

5 Estela conta que Simone Schwarz-Bart descreveu como foi o encontro dela com o futuro marido: ela chegou a Paris muito jovem e, ao sair de uma estação do metrô, não sabia que direção tomar para chegar a seu destino. Pediu informação justamente para ele. Além de responder, ele não a largou nunca mais. Explicou o caminho e resolveu acompanhá-la. Pouco tempo depois, casaram-se. Ficou fascinado por ela. $\mathrm{E}$ é fácil entender, porque ela é uma mulher fascinante, intuitiva. 
ia muito à Europa, ela ia bem menos, embora tivessem domicílio na França.

Depois de alguns dias, já nem falávamos da tradução. Fui à casa dela algumas vezes. Começou a me ensinar o que era o Caribe e a Guadalupe. Levou-me a um almoço de domingo em casa de uma destacada família (que ela, apesar de ser sempre convidada, não costumava frequentar) para que eu visse de perto o jeitão da elite local. Foi uma lição sociopolítico-cultural, e de vida, das mais importantes que já tive. Conhecer a Simone foi mesmo um presente.

Do Brasil, tivemos muitos contatos por telefone porque eu gosto de falar com ela. Depois nos encontramos em Paris, na década de 1990. Faço o possível para vê-la quando estou em Paris. Em 2011 nos encontramos no Les Deux Magots. André Schwarz-Bart já tinha falecido.

18. Você explicou em uma entrevista que, "na obra, ela cita, por exemplo, uma árvore que não existe no Brasil. Uma espécie similar é o jequitibá. Em comum acordo com Simone, batizou dessa forma na edição brasileira" (apud Melo, 2009, s/p). Qual é a importância desse comum acordo: um procedimento de trabalho seu, uma exigência da editora, uma solicitação da autora?

Nem sempre dá para discutir dúvidas da tradução com o autor. Mas, se houver alguma possibilidade, é o ideal. A árvore "courbaril" não existe no Brasil. Os antilhanos, por sua vez, não têm o jequitibá. Querendo fazer o máximo para acertar, conversei com ela sobre isso. Sempre procuro ficar o mais próximo possível do texto original.

\section{Como traduzir as especificidades da fauna e da flora?}

Eu me lembro de ter ido ao Jardim Botânico do Rio e consultado a equipe muito competente do setor de pesquisa. Fiz isso não apenas para o livro da Simone. Em outros momentos de dúvida sobre o vocabulário de botânica, sempre fui lá muito bem atendida. 
Consulto dicionários, obras de referência, mas acabo recorrendo aos amigos - médicos, psicólogos, psiquiatras e outros. Ligo para eles, peço socorro e eles não falham.

20. Para além da nomenclatura específica da fauna e da flora, quais os maiores desafios na tradução desse romance?

Tinha em mente todo o tempo que o romance era maravilhoso e que eu não podia estragá-lo, não podia arranhar aquela beleza. Em toda tradução, o importante é reler e sentir se o tom e a harmonia remetem ao original, se o texto flui. Fico muito atenta à musicalidade. É isso. Não existe uma maneira de validar a tradução, descobrir se aqui ou ali está o melhor possível. Claro que existem o certo e o errado, mas, quase sempre, o mais difícil é ser sensível às nuanças.

\section{Como você interpreta o desafio da tradução da oralidade na obra?}

Guardar a fidelidade ao que está sendo dito. Dizer da maneira como lhe parece - e aí entra a responsabilidade do tradutor - a mais próxima daquela que as pessoas entendem. As pessoas que você conhece, o seu meio. A prova seria fazer uma leitura em voz alta de determinados trechos. E, ao sentir que algo está emperrando a fluidez, apagar, mudar. É preciso buscar o tom natural.

22. Alguns críticos, como Mariella Aïta, reconhecem que Schwarz-Bart escreve na língua franco-crioula, língua marcada por mestiçagens linguísticas que se reconhecem, por exemplo, nos temas, na entonação e na sintaxe utilizados. Você reconhece essa língua? Como é possível para a arte da tradução espelhar a riqueza de línguas em contato no âmbito do texto? Como explicitar a presença do crioulo no discurso em francês?

Não reconheci essa língua. Percebi que era um francês fora do Hexágono que aparecia nas especificidades do vocabulário e no tom da obra. Claramente não era um francês da França. Mas o franco-crioulo 
não apresentou problemas para a tradução, não foi empecilho. Não senti necessidade de consultar um dicionário de crioulo ou alguém nesse sentido. Além do vocabulário específico e pontual das realidades que não existem em português, não me lembro de outras dificuldades que merecessem atenção especial.

23. Insistindo ainda nesse tema, Mariella Aïta afirma que "para Simone Schwarz-Bart chegar a um resultado significa aprender a passar, nesse processo de retranscrição, por diversas camadas linguísticas: a camada crioula, a camada francesa, a camada crioulo-francesa e, em seguida, o produto, o novo termo, a nova língua" (2010, p. 23).

Como a tradução vislumbra essas camadas linguísticas?

Eu me declaro incapaz de responder a isso e de entrar nessa seara. A teoria sobre um texto é bem diferente do processo de tradução do texto.

24. Antoine Berman afirma que escritores francófonos como Édouard Glissant e Simone Schwarz-Bart encarnam o trabalho ambivalente essencial à tradução de "para forçar sua língua a incorporar-se de estranheza, forçar a outra língua a transitar na sua língua materna" (2011, p. 18). Para Berman, eles imprimem sua "estranheza" na língua francesa ao mesmo tempo que tendem a empregar uma língua mais "pura” que a da França. Como você avalia essa dicotomia? Esses escritores seriam tradutores?

Não sei se podemos chamar esses autores de tradutores. O importante é que eles tenham noção do movimento que fazem. Como eles resolvem isso no texto que escrevem, vai depender da habilidade de cada um. Podemos comparar o trabalho desses escritores à atividade de tradução por causa da ambivalência de, ao mesmo tempo, estar próximo do original e ter de marcar as diferenças da língua para a qual se traduz. 
25. Além de você, Helena da Rosa Cortes de Lacerda e Roberto Cortes de Lacerda são autores do Dicionário de provérbios: francês, português, inglês, publicado em 2004. A crítica Kathleen Gyssels $(1996,1997)$ estuda o uso de provérbios na obra de Simone Schwarz-Bart, em geral, e no romance Pluie et vent sur Télumée Miracle, em particular. A oralitura está amplamente representada em obras caribenhas. Como traduzir os provérbios? Que lembranças você tem sobre os provérbios no romance em questão?

Não se traduz provérbio de jeito nenhum. Quando traduzi esse romance, ainda não tinha feito nenhum trabalho sobre provérbios. Não tenho lembrança de ter feito pesquisas sobre os provérbios existentes, busquei simplesmente uma correspondência de sentido. Hoje, decerto, eu procederia de modo diferente se tivesse de traduzir o romance. Esse dicionário foi um longo trabalho que nasceu da iniciativa de Roberto e Helena. Ela fez a parte do inglês, ele e eu fizemos a parte do francês.

26. O livro apresenta algumas canções. Como seu processo de tradução leva em conta o ritmo musical de Schwarz-Bart?

Minha preocupação é chegar o mais perto possível do original. Não observo métrica, tento guardar apenas o ritmo.

(Nesse momento, Estela coteja a primeira música do romance tanto na edição original quanto na tradução. Diz não se lembrar das músicas e quer conferir se traduziu de maneira satisfatória para si mesma).

Que medo. E se estiver mal traduzido? E se houver uma incongruência? [...] Esta musiquinha é muito fácil.

A música foi traduzida como "preciso de um marido pescador/ para me pescar uns dourados/ não sei se vocês sabem/ preciso de um marido pescador/ Ó remo da frente, ele me dá prazer/ ó remo de trás, ele me faz morrer" (1986, p. 15). No romance original, a música é "J’ai besoin d'un mari pêcheur/ pour me pêcher des daurades/ je ne sais pas si vous 
le savez/ j'ai besoin d'un mari pêcheur/ O rame devant il me fait plaisir/ o rame derrière il me fait mourir" (1995, p. 18).

Acho razoável a tradução. Olhe, até sob tortura, eu teria dito a mesma coisa...

27. A canadense Monique Bouchard optou pela existência de um glossário ao fim de um estudo sobre a obra Pluie et vent sur Télumée Miracle. Na sua tradução, não há glossário, tampouco nota explicativa do tradutor. Por que você optou por não utilizar esses paratextos? Quando eles lhe parecem fundamentais? Quando são dispensáveis?

Nunca foi cogitada a existência de um glossário nem de notas explicativas do tradutor. A editora não se manifestou a respeito. Esse foi um dos primeiros livros que traduzi e não pensei nessa possibilidade. Entretanto, no livro Adriana em todos os meus sonhos, de Depestre, publicado em 1996, apresentei um glossário, com oito laudas, de termos haitianos em língua crioula. No livro Apresentação de trabalhos monográficos de conclusão de curso, publicado na UFF, utilizei, à p. 83, uma folha desse glossário como modelo. No caso de Simone Schwarz-Bart, a editora não pediu nem eu pensei nisso. Hoje, eu possivelmente faria muitas coisas de outro modo.

É preciso atentar para o fato de notas explicativas e glossário provocarem interrupções no fluxo da leitura e poderem tornar-se infernais para o leitor, principalmente quando se trata de um romance. Não gosto muito, acredito que é melhor não abusar do paratexto.

28. Por quanto tempo se prolongou o processo de tradução? Quatro meses. 
29. Você tem conhecimento da recepção de Simone Schwarz-Bart à tradução brasileira desse romance?

Como de praxe, ela recebeu o livro pela editora. Não me lembro, infelizmente, de nenhum comentário ou reação dela sobre a tradução. Estive com ela em Paris depois da publicação, mas não me lembro de termos falado sobre isso.

Na época do lançamento de $A$ ilha da chuva e do vento, a editora organizou a vinda de Simone ao Brasil para a apresentação e divulgação do livro. Ela viria com o marido, mas, no aeroporto, na hora do embarque, ele declinou da viagem e convenceu Simone a não vir. Quando o voo chegou ao Rio, havia jornalistas no desembarque à espera do casal. Foi um grande desapontamento. Estava tudo organizado, muita gente querendo conhecê-la, e ela não veio. Nunca veio ao Brasil.

30. Com relação à tradução do título, por que você optou por $A$ ilha da chuva e do vento?

Foi uma escolha da editora, eu não interferi em nada. Márcio Sousa e a editora Maria José Silveira quiseram esse título. Pode parecer um título solto, muito aberto, mas ao mesmo tempo retoma a chuva e o vento do título original. Achei uma boa solução. Não dava para traduzir em português o nome da personagem. Não existe Telumea. E deixar aquele nome francês num livro brasileiro também não parecia boa opção. Às vezes, o tradutor sugere dois, três ou até mais títulos para que a editora opte pelo que lhe pareça mais adequado ao público brasileiro. Não foi o caso. O título já estava definido quando iniciei a tradução.

\section{Você tem vontade de traduzir outras obras de Simone Schwarz-Bart?}

Tive muita vontade, mas não foi possível, não surgiu nenhum convite. Quando voltei da Guadalupe, fui procurada por um diretor da Rede Globo em busca de peças de teatro em língua francesa. Sugeri a peça Ton beau capitaine, que tive a oportunidade de ver encenada em Paris ao lado da própria Simone Schwarz-Bart anos depois. Ela 
me convidou para a estreia da peça. Fazia tempo que não nos víamos. Foi na década de 1990. Eu trouxe o texto para o Brasil e me propus a traduzi-lo. Mas a Globo mudou o projeto e não houve tradução nem adaptação da peça de teatro. Fiquei com muita pena porque a peça é excelente. Além disso, ela merecia ter aqui outras obras traduzidas além de A ilha da chuva e do vento e de Joãozinho no Além.

32. Sua tradução completou, em 2016, trinta anos de publicação. Você já releu a tradução? Que balanço você faz da sua tradução? Esses trinta anos te levam a reavaliar algum aspecto da tradução?

Reli a tradução de $A$ ilha da chuva e do vento pela primeira vez depois dessa entrevista. Com certa apreensão, porque não sabia como eu dava conta de traduzir naquela época. Mas com a certeza de ter compreendido bem o original. Para as dúvidas sobre o vocabulário específico, havia consultado a própria autora, vários especialistas em botânica etc. Da releitura feita agora, achei o seguinte:

- algumas mudanças quanto ao nosso atual Vocabulário Ortográfico;

- pontuação desnecessária (vírgulas em demasia, por exemplo);

- poucas palavras que eu teria preferido hoje;

- alguns pequenos enganos "de datilografia" (como se dizia na época, porque o texto foi mesmo datilografado);

- correções mesmo, faria cinco ou seis. Mas nenhuma muito grave. 